\title{
On Single- and Multi-Market Unbiasedness of Fonward Exchange Rates: Some Evidence from Four Asian Countries
}

\author{
Razzaque H. Bhatti* \\ University of Azad Jammu \& Kashmir
}

\begin{abstract}
Long-run unbiasedness is tested between forward exchange markets of four Asian countries - Hong Kong, Japan, Malaysia and Singapore - vis-à-vis the U.S. and Japan using monthly data on spot and one-month forward exchange rates over the period 1985-1994. The results obtained by employing the Johansen [1988] maximum likelihood technique of cointegration are support ive of unbiasedness for two countries ( Malaysia and Singapore) against Japan but only one ( Singapore) against the U.S. The results also indicate that unbi asedness holds only in the case of forward exchange markets of Malaysia and Singapore relative to Japan not only when these markets are examined in iso lation from other Asian markets but also in a joint system they constitute. (JEL Classification: F 31)
\end{abstract}

\section{Introduction}

The last two decades have witnessed an enormous growth in the literature on the unbiasedness hypothesis. Associated with informationally effi-

* Correspondence Address: Kashmir Institute of Development Studies, University of Azad J ammu \& Kashmir, M uzaffarabad, Azad Kashmir, Pakistan; (Fax) 058-4717.

(C1997 - Institute for International E conomics, Sejong Institution. All rights reserved. 
cient foreign cur rency markets in which investors are rational and risk neutral, this hypothesis postulates that the forward exchange rate tends to fully reflect all available relevant information to predict the future spot exchange rate, forcing the expected return on forward speculation to be equal to zero. ${ }^{1}$ In essence, this hypothesis stipulates that the forward exchange rate is an unbiased and an efficient forecaster of the future spot exchange rate, implying unbiasedness in the forward exchange market. However, most studies investigating the validity of the unbiasedness hypothesis have documented evidence which usually indicates the failure of the hypothesis.

Empirical work on the unbiasedness hypothesis ${ }^{2}$ has generally followed four main directions. ${ }^{3}$ First, the earliest work carried out, inter alia, by Frankel [1980], Giddy and Dufey [1975] and Giddy [1977] tested unbiasedness in the forward exchange market by examining if the forward forecasting error is significantly different from zero. Second, the majority of researchers, including Lai and Lai [1991], Copeland [1991, 1993], M oore and Copeland [1995], Ukpolo [1995] and M asih and M asih [1995], tested the hypothesis by examining if the forward rate is an unbiased predictor of the market's expectations of the future spot rate. Third, a number of

1. The concept of market efficiency followed here draws heavily on Fama [1970] who defines an efficient market as one in which prices always fully reflect available information.

2. Testing unbiasedness is also viewed as an indirect test of uncovered interest parity because it relies on a maintained hypothesis of covered interest parity. On the other hand, a direct test of uncovered interest parity is conducted using data on both foreign exchange and interest rates 〈see, for example, B hatti and M oosa, [1995]).

3. Enormous empirical work has also been conducted to rationalise the failure of the hypothesis. This includes work using survey data on expectations $\langle$ see, for example, F rankel and Froot, [1990]; and Cavaglia et al, [1994]> to examine if the failure of the hypothesis can be attributed to irrationality or to risk premia or to some combination of both, applying filter rules 〈see, for example, Dooley and Shafer, [1983]; and Levich and Thomas, [1993] $\rangle$ to examine if the expectations about exchange rates are rational, developing various models 〈F ama, [1984]; Wolff, [1987]; Peel, [1993]; and M iles, [1993] $\rangle$ to examine if the failure of unbiasedness can be attributed to the presence of risk premia and identifying the factors accounting for the bias in the forward exchange rate 〈see, for example, M acDonald, [1985]; Korajczyk, [1985]; Pittis, [1992]; and Bachman, [1992]〉. For a comprehensive survey of these and other aspects of the hypothesis /see B hatti [1995], pp. 120-69 and M oosa and Bhatti [1997], pp. 82-93; 270-78>. 
researchers, among others, Fama [1984], Taylor [1988] and Zietz and Homaifar [1994], tested the hypothesis by examining if the forward premium is an unbiased predictor of the market's expectations of the future rate of change of the spot exchange rate. Finally, studies conducted, inter alia, by Geweke and Feige [1979], H sieh [1984], M acD onald and Taylor [1991] and Ligeralde [1994] tested single- and multi-market efficiency by examining whether the forward markets around the world are efficient in isolation or in a joint system they constitute. A general conclusion that emerges from empirical research in all the directions is that unbiasedness does not hold. ${ }^{4}$

It is worth noting that most of the above studies investigated unbiasedness in forward exchange markets of major industrial countries, with only little attention focused on those developed in some Asian countries. The objective of this paper is to test single- and multi-market unbiasedness in forward exchange markets of the four Asian countries - Hong Kong, Japan, $M$ alaysia and Singapore - by employing the J ohansen [1988] maximum likelihood cointegration test. The remainder of the paper is organised as follows. Section II gives a brief description of the hypothesis and model specification used to test single- and multi-market unbiasedness in forward exchange markets. Section III deals with the data sources, methodology and empirical results. Concluding remarks are presented in the final section.

\section{The Hypothesis and Model Specification}

The unbiasedness hypothesis posits that in perfectly competitive and informationally efficient markets for forward foreign exchange, in which economic agents are rational and risk neutral, the forward premium (forward rate) tends to be an unbiased and an efficient predictor of the market's expected rate of change of the spot rate (expected spot rate). This hypothesis, which is typically derived from covered and uncovered interest parity conditions, is usually represented by the following two model specifications ${ }^{5}$

$$
\mathrm{s}_{\mathrm{t}+1}^{\mathrm{e}}-\mathrm{s}_{\mathrm{t}}=\mathrm{f}_{\mathrm{t}}-\mathrm{s}_{\mathrm{t}}
$$

4. A number of studies, however, do lend some support to unbiasedness $\langle$ see, for example, Frenkel, [ 1980]; M acD onald, [1985]; Zietz and Homaifar, [ 1994]; and Ligeralde, [1994]).

5. For the derivation of these model specifications see B hatti [1995, pp. 111-12]. 


$$
\mathrm{s}_{\mathrm{t}+1}^{\mathrm{e}}=\mathrm{f}_{\mathrm{t}}
$$

where $s_{t}$ is (the logarithm of) the spot exchange rate, $s_{t+1}^{e}$ is (the logarithm of) the future spot exchange rate expected to prevail at time $t+1$ and $f_{t}$ is (the logarithm of) the forward exchange rate set at time $t$ for deliver $y$ at time $t+1$. Equations (1) and (2) represent two alternative specifications of the unbiasedness hypothesis: the 'forward premium' and the 'forward rate' specifications respectively.

Now, if we assume that the market's expectations about the future spot exchange rate are rational, then the spot exchange rate realised at time $t+1$ will differ from the expected spot exchange rate by a zero mean, serially uncorrelated error term. Formally, this is represented by

$$
\mathrm{s}_{\mathrm{t}+1}=\mathrm{s}_{\mathrm{t}+1}^{\mathrm{e}}+v_{\mathrm{t}+1}
$$

such that $\mathrm{E}\left(\mathrm{v}_{\mathrm{t}+1} \mid \Omega_{\mathrm{t}}\right)=0$ and $\mathrm{E}\left(\mathrm{v}_{\mathrm{t}+1} \mathrm{v}_{\mathrm{t}+1-\mathrm{i}}\right)=0 \forall_{\mathrm{i}} \neq 0$. Substituting equation (3) into equations ( 1 ) and (2), we obtain

$$
\begin{aligned}
& s_{t+1}-s_{t}=f_{t}+v_{t+1} \\
& s_{t+1}=f_{t}+v_{t+1}
\end{aligned}
$$

where $v_{t+1}$ is the forward forecasting error, which also implies speculative profit which can be made by buying the foreign currency forward at the price $f_{t}$ and selling it spot at the price $s_{t+1}$. If $v_{t+1}$ has a mean zero and is serially uncor related, then the forward premium (forward rate) turns out to be an unbiased and an efficient forecaster of the expected rate of change of the spot rate (expected spot rate).

The model specification suggested here to test unbiasedness in the forward exchange market is represented by equation (5), which is based on level data on exchange rates. There are several benefits of testing unbiasedness using a model specification based on level rather than on differenced data on exchange rates. First, a model using level data on exchange rates is conducive to employing cointegration analysis. Second, a level data model produces estimates converging on the true parameter values at the rate $\mathrm{N}$ rather than $\div N$ (where $N$ is the sample size) for a differenced data model. ${ }^{6}$

6. See Stock [1987] and Park and Phillips [1988]. 
Finally, while stationary series exhibit stochastic correlation with differenced data regressors, this problem does not arise when level data are used since the order of integration of a nonstationary regressor dominates that of the stationary risk premium.

It is important to note that unbiasedness is unlikely to hold precisely if market agents are risk averse. Therefore, if we allow for the presence of a non-zero risk premium, $\rho_{t}$, then equation (5) can be rewritten as follows

$$
s_{\mathrm{t}+1}=\mathrm{f}_{\mathrm{t}}+\rho_{\mathrm{t}}+v_{\mathrm{t}+1}
$$

Let us assume that the behaviour of a zero risk premium is represented by

$$
\rho_{\mathrm{t}}=\mathrm{a}+\mathrm{u}_{\mathrm{t}}
$$

where $a$ is the mean value of the risk premium which is assumed to be zero and $u_{t}$ is white noise. Substituting (7) into (6) we obtain

$$
\mathrm{s}_{\mathrm{t}+1}=\mathrm{f}_{\mathrm{t}}+v_{\mathrm{t}+1}+\mathrm{a}+\mathrm{u}_{\mathrm{t}}
$$

which in an empirically testable form can be written as

$$
\mathrm{s}_{\mathrm{t}+1}=\beta_{0}+\beta_{1} \mathrm{f}_{\mathrm{t}}+\omega_{\mathrm{t}+1}
$$

where $\omega_{t+1}=v_{t+1}+u_{t}$ is the error term reflecting the impact of news, and $\beta_{0}$ is a constant term reflecting the value of the risk premium as well as other factors such as transaction costs. The forward rate appears to be an unbiased forecast of the future spot rate if the restriction $\left(\beta_{0}, \beta_{1}\right)=(0,1)$ is not rejected. This forecast is also efficient if the residual, $\omega_{t+1}$, contains no information relevant to improve the forecast, such that $\mathrm{E}\left(\omega_{\mathrm{t}+1} \omega_{\mathrm{t}+1-\mathrm{i}}\right)=0, \forall_{\mathrm{i}} \neq 0$.

The model represented by equation (9) is used to test unbiasedness in a country's forward market in complete isolation from other forward markets. This represents single-market unbiasedness because the assumption underlying this model is that market agents make use of the information contained only in the domestic cur rency forward rate, but not in other currency forward rates, to predict the movements in the future spot rate. But it must be noted that the information contained in other currency forward rates, particularly those of strong currencies, may also help improve the prediction about the future spot rates. However, if market agents fail to improve their predictions about the future spot rates using the information contained in other currency forward rates, then own forward rates will tend to be 
unbiased and efficient forecasters of the market's expectations of the future spot rates and hence the forward markets around the world tend to be efficient jointly. ${ }^{7}$ This is known as multi-market unbiasedness which can be tested by fitting the following regression

$$
S_{t+1}^{i}=0+{ }_{1} f_{t}^{i}+\sum_{j=1}^{n} j f_{t}^{j}+{ }_{t+1}^{i}
$$

where $\mathrm{f}_{\mathrm{t}}^{\mathrm{i}}$ represents the domestic currency forward rates and $\mathrm{f}_{\mathrm{t}}^{\mathrm{j}}$ represents other currency forward rates. For single-market unbiasedness of forward rates to exist, the coefficients on the terms $\mathrm{ft}_{\mathrm{t}}^{j}$ should be zero. On the other hand, for multi-market unbiasedness of forward rates to hold the restrictions $\beta_{0}=0, \beta_{1}=1$ and $\gamma_{j}=0$ must not be rejected jointly.

\section{Data, Methodology and Empirical Results}

Long-run single- and multi-market unbiasedness of forward rates is tested for four Asian currencies ${ }^{8}$ - Hong Kong dollar, HD, Japanese yen, JY, M alaysian Ringgit, M R, and Singapore dollar, SD - vis-à-vis the U.S. dollar and the Japanese yen on the basis of equations (9) and (10) respectively. For this purpose, monthly, nonoverlapping, data were collected on end of month spot and one-month forward exchange rates covering the period 1985:11994:12. All data were obtained from Datastream.

The methodology employed for testing unbiasedness in forward markets will be cointegration analysis, which is superior to conventional regression analysis because it produces superconsistent estimates of the regression

7. Alternatively single- and multi-market unbiasedness of forward rates cannot be rejected if the forward forecasting errors of the home currency are serially uncorrelated not only with their own lagged values but also with the lagged values of the forward forecasting errors of other currencies 〈see, for example, Geweke and Feige, [1979]; and Hansen and Hodrick, [1980]).

8. One reason for picking up these currencies is that commercial banks in the countries under investigation are free to deal forward in almost all currencies. M oreover, no official forward cover is provided in these countries, except $M$ alaysia in which forward premiums and discounts are roughly equal to those which the commercial banks charge their customers. Although, there are some other Asian countries (e.g. Indonesia) in which forward rates are freely quoted by commercial banks, the data needed is not available for them. 
parameters, despite the presence of such problems as simultaneity, serial correlation and heteroscedasticity 〈Stock, [1987]〉. However, Engle and Granger [1991] warn against using the conventional t statistic in making statistical inferences about the estimated coefficients, since these do not have limiting normal distribution. This problem arises only in the case of the residual-based cointegration tests ${ }^{9}$ but can however be overcome by employing the West [1988] corrected t statistic. On the other hand, there arises no such problem in the case of the Johansen test because it allows not only to test for cointegration but also to test for restrictions on the estimated coefficients.

F or a pair of variables, for example $s_{t+1}$ and $f_{t}$ underlying equation (9), to form a cointegrating (long-run) relationship a necessary but not a sufficient condition is that both of the variables are integrated of the same order. If $\mathrm{s}_{\mathrm{t}+1}$ and $f_{t}$ are $I(1)$, then the sufficient condition requires the linear combination thereof to be integrated of order zero (i.e. $\omega_{t+1} \sim l(0)$ ). However, it must be noted that cointegration is a necessary, but not a sufficient condition, for long-run single- and multi-market unbiasedness to exist in forward markets. The sufficient condition requires the restrictions $\left(\beta_{0}, \beta_{1}\right)=(0,1)$ and $\left(\beta_{0}, \beta_{1}\right.$, $\left.\gamma_{j}\right)=(0,1,0)$ to be satisfied in equations (9) and (10) respectively.

Testing long-run unbiasedness is carried out on the basis of the J ohansen [1988] maximum likelihood cointegration test which is considered to be more powerful than the residual-based cointegration tests on the following grounds. First, its results are invariant with respect to the direction of normalisation. Second, it provides estimates of all cointegrating vectors existing within a system of variables. Third, it allows to test a priori restrictions on the coefficients of the cointegrating vectors imposed by the economic theory. Finally, it fully captures the underlying time series properties of data. The J ohansen test is based on the multivariate vector autoregression representation (VAR) of $n$ variables

$$
Z_{t}=+\sum_{r=1}^{k} \Pi_{r} Z_{t-r}+{ }_{t}
$$

where $Z_{t}$ is $n \times 1$ vector of I (1) variables, $\Pi_{1}, \Pi_{2}, \ldots, \Pi_{k}$ are matrices of

9. For example the Engle-Granger [1987] and the Phillips-Ouliaris [1990] tests. 
unknown parameters, $\mu$ is a vector of constants, $\varepsilon_{t}$ is a vector of Gaussian error terms and $k$ is the maximum lag or the order of the VAR. This model can be reparameterised as follows

$$
\Delta \mathrm{Z}_{\mathrm{t}}=+\sum_{\mathrm{r}=1}^{\mathrm{k}-1} \Gamma_{\mathrm{r}} \Delta \mathrm{Z}_{\mathrm{t}-\mathrm{r}}+\mathrm{RZ}_{\mathrm{t}-\mathrm{k}}+\mathrm{t}
$$

where $\Gamma=-\mathrm{I}+\Pi_{1}+\Pi_{2}+\ldots+\Pi_{\mathrm{k}}$ and $\mathrm{I}$ is the identity matrix. $\Pi$ is the cointegrating matrix such that $\Pi Z_{t}=0$ represents long-run equilibrium. An important question which needs to be explained here concerns the rank, $r$, of the matrix $\Pi$, and there are three possibilities. If $\Pi$ has a full rank matrix (i.e. $r=n$ ), any linear combination of $Z_{t}$ variables will be stationary. In the twovariable model represented by equation (9) this can only occur if $s_{t+1}$ and $f_{t}$ are stationary, which means that the correct model will be in level rather than in first differences. If, on the other hand, $\Pi$ has zero rank (i.e. $r=0$ ), then any linear combination of $Z_{t}$ variables will be nonstationary, which means that the variables are not cointegrated and the proper model will be in first differences. Finally, If $\Pi$ has a less than full rank matrix $(0<r<n)$ then we can write

$$
\Gamma=\alpha \beta^{\prime}
$$

where the columns of the $n \times r$ matrix $\beta$ are the cointegrating vectors and the columns of the $n \times r$ matrix $\alpha$ are error-correction coefficients measuring the speed of convergence of the dependent variables towards the long-run equilibrium state. The following are important steps involved in the application of the J ohansen technique of cointegration.

(1) Regress $\Delta Z_{t}$ and $Z_{t-k}$ on the lagged differences of $\Delta Z_{t}$ and a constant as follows

$$
\begin{aligned}
& \Delta \mathrm{Z}_{\mathrm{t}}=+\sum_{\mathrm{r}=1}^{\mathrm{k}-1} \Gamma_{0 \mathrm{r}} \Delta \mathrm{Z}_{\mathrm{t}-\mathrm{r}}+\mathrm{V}_{0 \mathrm{t}} \\
& \Delta \mathrm{Z}_{\mathrm{t}-\mathrm{k}}=+\sum_{\mathrm{r}=1}^{\mathrm{k}-1} \Gamma_{1 \mathrm{r}} \Delta \mathrm{Z}_{\mathrm{t}-\mathrm{r}}+\mathrm{V}_{1 \mathrm{t}}
\end{aligned}
$$

(2) Extract the residuals $V_{0 t}$ from equation (14) and $V_{1 t}$ from equation (15).

(3) Use the residuals $V_{0 t}$ and $V_{1 t}$ to calculate $n$-squared canonical correlations (or the eigenvalues) with order $\lambda_{1}>\lambda_{2}>\lambda_{3}>\ldots>\lambda_{n}$. 
(4) Use the eigenvalues to construct two test statistics for testing the existence of the number of unique cointegrating vectors between $Z_{t}$ variables. The first statistic, known as the maximum eigenvalue ( $M a x$ ) test, evaluates the null hypothesis that there are exactly $r$ cointegrating vectors, and is given by

$$
M A X=-T \ln (1-r+1)
$$

where $T$ is the sample size. The second statistic, known as the Trace test, evaluates the null hypothesis that there are at most $r$ cointegrating vectors, and is given by

$$
\text { Trace }=-T \sum_{\mathrm{t}=\mathrm{r}+1}^{\mathrm{n}} \ln \left(1-{ }_{\mathrm{t}}\right)
$$

where $\lambda_{r+1}, \lambda_{r+2}, \ldots \lambda_{n}$ is the $n-r$ smallest squared canonical cor relations of $V_{0 t}$ with respect to $V_{1 t}$.

Johansen and Juselius [1990] note that the power of the Trace test is lower than the Max test. In both the cases the null hypothesis is rejected if the calculated value of the statistic is greater than the critical value as tabulated in J ohansen and J uselius [1990].

B efore testing single- and multi-market unbiasedness of forward rates for cointegration, unit root tests are first performed to find out if the variables underlying equations (9) and (10) are integrated of the same order. For this purpose, the Phillips-Ouliaris [1990] $\hat{Z}_{\alpha}$ and $\hat{Z}_{\mathrm{t}}$ test statistics are used. ${ }^{10}$ The results, which are presented in Table 1 , are consistent in indicating that onemonth forward and corresponding expected spot exchange rates of all currencies against both the U.S. dollar and the J apanese yen are I(1) in levels and $\mathrm{I}(0)$ in first differences.

Having found all forward and expected spot exchange rates to be integrated of the same order, it is now possible to proceed to testing for cointegration between them. This is carried out on the basis of the J ohansen [1988] maximum likelihood test using two test statistics: the Max and the Trace.

10 The Phillips-O uliaris [1990] test is based on $\hat{Z}_{\alpha}$ and $\hat{Z}_{t}$ statistics, which were originally proposed by Phillips [1987]. These statistics are more robust to a wide variety of serial correlation, time dependent heteroscedasticity and regime changes. For a comprehensive survey on these and other unit root statistics, including those proposed by Phillips-Perron [1988], 〈see M oosa and Bhatti [1997], pp. 148-51;172-73〉. 
Table 1

Testing Exchange Rates for Unit Root

\begin{tabular}{|l|c|c|c|c|c|}
\hline \multirow{2}{*}{ Country } & \multirow{2}{*}{ Variable } & \multicolumn{2}{|c|}{ Level } & \multicolumn{2}{c|}{ First Difference } \\
\cline { 3 - 6 } & & $\hat{Z}_{\alpha}$ & $\hat{\mathrm{Z}}_{\mathrm{t}}$ & $\hat{\mathrm{Z}}_{\alpha}$ & $\hat{\mathrm{Z}}_{\mathrm{t}}$ \\
\hline \multirow{2}{*}{$\mathrm{HD}$} & $\mathrm{S}_{\mathrm{t}+1}$ & -9.07 & -2.14 & $-109.56^{*}$ & $-19.79^{*}$ \\
& $\mathrm{f}_{\mathrm{t}}$ & -14.51 & -2.75 & $-106.61^{*}$ & $-18.56^{*}$ \\
\hline \multirow{2}{*}{$\mathrm{JY}$} & $\mathrm{S}_{\mathrm{t}+1}$ & -3.83 & -2.43 & $-134.02^{*}$ & $-11.15^{*}$ \\
& $\mathrm{f}_{\mathrm{t}}$ & -3.33 & -2.13 & $-132.74^{*}$ & $-11.17^{*}$ \\
\hline \multirow{2}{*}{$\mathrm{MR}$} & $\mathrm{S}_{\mathrm{t}+1}$ & -9.54 & -2.29 & $-116.61^{*}$ & $-18.56^{*}$ \\
& $\mathrm{f}_{\mathrm{t}}$ & -11.00 & -2.56 & $-136.30^{*}$ & $-14.24^{*}$ \\
\hline \multirow{2}{*}{$\mathrm{SD}$} & $\mathrm{S}_{\mathrm{t}+1}$ & 0.52 & 0.65 & $-104.52^{*}$ & $-12.11^{*}$ \\
& $\mathrm{f}_{\mathrm{t}}$ & 0.73 & 0.89 & $-94.94^{*}$ & $-11.76^{*}$ \\
\hline \multirow{2}{*}{$\mathrm{HD} / \mathrm{JY}$} & $\mathrm{S}_{\mathrm{t}+1}$ & -3.90 & -2.45 & $-132.10^{*}$ & $-11.00^{*}$ \\
& $\mathrm{f}_{\mathrm{t}}$ & -3.36 & -2.12 & $-141.16^{*}$ & $-11.07^{*}$ \\
\hline \multirow{2}{*}{$\mathrm{MR} / \mathrm{JY}$} & $\mathrm{S}_{\mathrm{t}+1}$ & -4.15 & -2.66 & $-124.51^{*}$ & $-10.18^{*}$ \\
& $\mathrm{f}_{\mathrm{t}}$ & -3.99 & -2.55 & $-168.24^{*}$ & $-11.38^{*}$ \\
\hline \multirow{2}{*}{$\mathrm{SD} / \mathrm{JY}$} & $\mathrm{S}_{\mathrm{t}+1}$ & -7.49 & -2.93 & $-164.69^{*}$ & $-11.28^{*}$ \\
& $\mathrm{f}_{\mathrm{t}}$ & -6.88 & -2.75 & $-132.74^{*}$ & $-11.28^{*}$ \\
\hline
\end{tabular}

* Significant at the 5\%level.

Testing the restrictions implied by single- and multi-market unbiasedness of forward rates is carried out on the basis of the procedure outlined in Johansen and Juselius [1990]. The results of cointegration and coefficient restrictions tests on single- and multi-market unbiasedness of forward rates are presented in Tables 2 and 3.

The results of cointegration tests for single-market unbiasedness, as shown in Table 2, are more supportive for Asian forward rates against the Japanese yen rather than against the U.S. dollar as both the Max and Trace statistics consistently reject the null hypothesis of no cointegration $(r=0)$ against the alternative of one cointegrating vector $(r=1)$ between the underlying one-month forward and corresponding future spot rates. $M$ oreover, cointegration of single-market unbiasedness seems to be relatively more stable in all cases against the Japanese yen, and not against 


\section{Table 2}

Testing Single-Market Unbiasedness $\left(\mathrm{s}_{\mathrm{t}+1}=\beta_{0}+\beta_{1} \mathrm{f}_{\mathrm{t}}+\omega_{\mathrm{t}+1}\right)$

\begin{tabular}{|l|r|r|r|r|r|r|r|}
\hline \multicolumn{1}{|c|}{ Test } & HD & HD/JY & JY & M R & M R/JY & SD & SD/JY \\
\hline$\beta_{0}$ & -0.366 & 0.010 & -0.628 & -0.048 & 0.030 & -0.002 & -0.182 \\
$\beta_{1}$ & 1.179 & 1.004 & 1.013 & 1.049 & 1.008 & 1.006 & 0.966 \\
\hline Max $(r=0)$ & $16.84^{*}$ & $17.10^{*}$ & 13.33 & $17.84^{*}$ & $26.44^{*}$ & $17.25^{*}$ & $25.26 *$ \\
$\operatorname{Trace}(r=0)$ & 18.66 & $27.45^{*}$ & $20.71^{*}$ & $25.57^{*}$ & $39.85^{*}$ & $27.93^{*}$ & $36.63^{*}$ \\
$\operatorname{Max}(r=1)$ & 1.83 & $10.35^{*}$ & 7.38 & 7.73 & $13.41^{*}$ & $10.68^{*}$ & $11.38^{*}$ \\
$\operatorname{Trace}(r=1)$ & 1.83 & $10.35^{*}$ & 7.38 & 7.73 & $13.41^{*}$ & $10.68^{*}$ & $11.38^{*}$ \\
$\chi^{2}\left(\beta_{0}, \beta_{1}=0,1\right)$ & $7.02^{*}$ & $6.20^{*}$ & $7.07^{*}$ & 1.29 & 1.33 & $7.91^{*}$ & 4.05 \\
\hline
\end{tabular}

* Significant at the $5 \%$ level.

the U.S. dollar, as the null hypothesis of one cointegrating vector $(r=1)$ against the alternative of two cointegrating vectors $(r=2)$ is also significantly rejected in all cases. On the other hand, the results show that while the null hypotheses of no and one cointegrating vector is rejected by both the Max and Trace statistics for SD, only the former is rejected by both the statistics for MR. For HD and JY even the null of no cointegration is not rejected consistently by these statistics. Although these empirical results are supportive of cointegration between forward and future spot rates in almost all cases against both the Japanese yen and the U.S. dollar, this evidence is not sufficient to favour unbiasedness of forward rates because cointegration is a necessary but not a sufficient condition for unbiasedness. The sufficient condition requires the restriction of single-market unbiasedness, $\left(\beta_{0}, \beta_{1}\right)=(0,1)$, to be satisfied. The results of coefficient restrictions test indicate that single-market unbiasedness holds only for three forward rates (MR, MR/JY and SD/JY). The results of unbiasedness for JY are consistent with those obtained by Lai and Lai [1991] and Copeland [1991, 1993] who employed the same procedure to testing the joint hypothesis of unbiasedness and no-risk premium. Similarly, the results for SD are consistent with those obtained by $\mathrm{M}$ acD onald and $\mathrm{Ta}$ [1987] but in direct contrast with those obtained by Tse [1986]. These studies tested unbiasedness for Singapore against the U.S. over the peri- 
Table 3

Testing Multi-Market Unbiasedness $\left(\mathrm{s}_{\mathrm{t}+1}^{\mathrm{i}}=\beta_{0}+\beta_{1} \mathrm{f}_{\mathrm{t}}^{\mathrm{i}}+\sum_{\mathrm{j}=1}^{n} \gamma_{\mathrm{j}} \mathrm{ft}_{\mathrm{t}}^{\mathrm{j}}+v_{\mathrm{t}+1}^{\mathrm{i}}\right)$

\begin{tabular}{|c|c|c|c|c|c|c|c|}
\hline Test & HD & $H D / J Y$ & JY & $M R$ & $M R / J Y$ & SD & $\mathrm{SD} / J \mathrm{Y}$ \\
\hline$\beta_{0}$ & -7.803 & 0.044 & 0.339 & -0.544 & -0.053 & -0.097 & 0.007 \\
\hline$\beta_{1}$ & -2.928 & 0.958 & 0.997 & 0.899 & 0.949 & 1.007 & 0.996 \\
\hline$\gamma_{1}$ & 0.004 & -0.002 & 0.015 & -0.007 & -0.004 & -0.002 & 0.015 \\
\hline$\gamma_{2}$ & 0.106 & 0.044 & -0.030 & 0.002 & 0.059 & -0.016 & -0.013 \\
\hline$\gamma_{3}$ & 0.173 & & -0.149 & 0.333 & & 0.058 & \\
\hline $\operatorname{Max}(r=0)$ & $30.70^{*}$ & $30.63 *$ & 31.77 & $47.52^{*}$ & $43.84 *$ & $36.39 *$ & $34.99 *$ \\
\hline Trace $(r=0)$ & $91.52^{*}$ & $65.14 *$ & 91.91* & $113.86 *$ & 83.73* & 107.37* & $78.76^{*}$ \\
\hline $\operatorname{Max}(r=1)$ & $27.12^{*}$ & $18.74 *$ & 23.97 & $28.92^{*}$ & $25.40 *$ & 27.87 & $29.14 *$ \\
\hline Trace $(r=1)$ & $60.82 *$ & $34.52 *$ & $60.12 *$ & $66.34 *$ & 39.73* & $70.98 *$ & $43.77^{*}$ \\
\hline 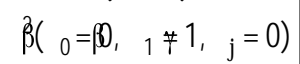 & $16.24 *$ & $13.25 *$ & $22.12^{*}$ & $12.54 *$ & 9.32 & $24.51^{*}$ & 9.32 \\
\hline
\end{tabular}

* Significant at the $5 \%$ level.

ods $1976-83$ and $1978-83$ respectively.

The results of cointegration tests for multi-market unbiasedness, as shown in Table 3, are also more supportive for Asian forward rates against the J apanese yen rather than against the U.S. dollar. M oreover, the results of coefficient restrictions test indicate that multi-market unbiasedness holds only for two for ward rates (MR/JY and SD/JY).

\section{Conclusion}

This paper investigates long-run unbiasedness of one-month forward exchange rates in predicting the corresponding future spot exchange rates within four Asian forward exchange markets - Hong Kong, J apan, $M$ alaysia and Singapore - vis-à-vis the U.S. and J apan. Tests are carried to examine the presence of single- and multi-market unbiasedness in forward markets of the countries under consideration. The results obtained by employing the J ohansen maximum likelihood procedure indicate that in three out of seven cases forward rates appear to be unbiased predictors of the market's expectations of the future spot rates. The results also show that unbiasedness holds only in the case of forward exchange markets of $\mathrm{M}$ alaysia and Singa- 
pore not only when these markets are looked at in complete isolation from other Asian markets but also when they are looked at as a joint system.

\section{References}

Bachman, D. [1992], "The Effect of Political Risk on the Forward Exchange Bias: the Case of Elections," Journal of International M oney and Finance, 11; pp. 208-219.

B hatti, R. H. [1995], International Parity Conditions: An Empirical Investiga tion, Unpublished Ph.D. Thesis, Sheffield University M anagement School.

B hatti, R. H. and M oosa, I. A. [1995], "An Alternative Approach to Testing Uncovered Interest Parity," A pplied E conomics Letters, 2; pp. 478-481.

Cavaglia, S.F.G., Verschoor, W. F. C. and Wolff, C.C.P. [1994], "On the Biasedness of F orward F oreign Exchange Rates: Irrationality or Risk Premia?," Journal of Business, 67; pp. 321-343.

Copeland, L.S. [1991], "Cointegration Tests with Daily Exchange Rate

Data," Oxford Bulletin of Economics and Statistics, 53; pp. 185-198.

Copeland, L.S. [1993], "E fficiency of the Forward M arket Day by Day and M onth by M onth," Applied Financial Economics, 3; pp. 79-87.

Dooley, M .P. and Shafer, J. [1983], "Analysis of Short Run Exchange Rate Behaviour: $M$ arch 1973-November 1981, in Bigman, D. and Taya, T. (eds), Exchange Rate and Trade Instability: Causes, Consequences, and Remedies, Cambridge, M assachusetts, Ballinger Publishing.

Engle, R.F. and Granger, C.W.J . [1987], "Cointegration and Error Correction: Representation, Estimation and Testing," Econometrica, 55; pp. 251-76.

Engle, R. F. and Granger, C. W. J. (eds) [1991], Long-Run E conomic Relation ships: Readings in Cointegration, Oxford University Press .

Fama, E. F. [1970], "Efficient Capital Markets: A Review of Theory and Empirical Work," Journal of Finance, 25; pp. 383-417.

Fama, E.F. [1984], "Forward and Spot Exchange Rates," Journal of M onetary Economics, 14; pp. 319-338.

Frankel, J.A. [ 1980], "Tests of Rational Expectations in the Forward Exchange M arket," Southern E conomic Journal, 46; pp. 1083-1101. 
Frankel, J.A. and Froot, K.A. [1990], "Exchange Rate Forecasting Techniques, Survey $D$ ata and Implications for the Foreign Exchange $M$ arket," NBER Working Paper, No. 3470.

Frenkel, J.A. [1980], "Exchange Rates, Prices, and M oney: Lessons from the 1920's," American Economic Review, Papers and Proceedings, 70; pp. 235-242.

Geweke, J . and Feige, E. [ 1979], "Some J oint Tests of the E fficiency of M arkets for Forward Foreign Exchange," Review of E conomics and Statis tics, 61; pp. 334-341.

Giddy, I.H. [1977], "Term Structure of and Expectations in the M oney and Foreign Exchange M arkets," Columbia University Graduate School of Business Working Paper.

Giddy, I.H. and Dufey, G. [1975], "The Random Behaviour of Flexible Exchange Rates," Journal of International Business Studies, 6; pp. 1-32. Hansen, L.P. and Hodrick, R.J . [1980], "Forward Exchange Rates as Optimal Predictors of Future Spot Rates: An E conometric Analysis," Journal of Political Economy, 88; pp. 829-853.

H sieh, D.A. [1984], "Tests of Rational Expectations and No Risk Premium in Forward Exchange M arkets," Journal of International E conomics, 17; pp. 173-184.

Johansen, S. [1988], "Statistical Analysis of Cointegrating Vectors," Journal of E conomic Dynamics and Control, 12; pp. 231-54.

Johansen, S. and J uselius, K. [1990], "M aximum Likelihood Estimation and Inference on Cointegration with Applications to the Demand for M oney," Oxford Bulletin of E conomics and Statistics, 52; pp. 169-210.

Korajczyk, R.A. [1985], "The Pricing of Forward Contracts for Foreign Exchange, Journal of Political Economy, 93; pp. 346-368.

Lai, K.S. and Lai, M . [1991], "A Cointegration Test for M arket Efficiency," Journal of F utures M arkets, 11; pp. 567-575.

Levich, R.M . and Thomas, L.R. [1993], "The Significance of Technical Trading-Rule Profits in the Foreign Exchange M arket: A Bootstrap Approach," Journal of International Money and Finance, 12; pp. 451474.

Ligeralde, A.V. [1994], "Simple Foreign Exchange M arket Efficiency Revisited," E conomics Letters, 46; pp. 257-262. 
M acDonald, R. [1985], "'N ews' and the 1920s Experience with Floating Exchange Rates," E conomics Letters, 17; pp. 379-383.

M acDonald, R. and Ta, G. [1987], "The Singapore Dollar: Tests of the Efficient $\mathrm{M}$ arkets Hypothesis and the Role of 'N ews'," Applied Economics, 19; pp. 569-579.

M acD onald, R. and Taylor, M .P. [1991], "Risk, E fficiency and Speculation in the 1920s Foreign Exchange M arket: An Overlapping Data Analysis," Weltwir tschaftliches Archiv, 127; pp. 500-523.

M asih, A.M .M . and M asih, R. [1995], "Investigating the Robustness of Tests of the Market Efficiency Hypothesis: Contributions from Cointegration Technique on the Canadian Floating Dollar," Applied Financial E conomics, 5; pp. 139-150.

Miles, D.K. [1993], "Time-Varying Risk Premia and Bias in the Foreign Exchange M arket," Applied Financial Economics, 3; pp. 217-230.

Moore, M.J. and Copeland, L.S. [1995], "A Comparison of Johansen and Phillips-Hansen Cointegration Tests of Forward M arket Efficiency: Baillie and Bollerslev Revisited," E conomics Letters, 47; pp. 131-135.

M oosa, I.A. and B hatti, R.H. [1994], "Testing the Effectiveness of Arbitrage and Speculation under Flexible Exchange Rates," Economia Internazionale, 47; pp. 392-408.

M oosa, I.A. and Bhatti, R.H. [1997], "International Parity Conditions: Theo ry, E conometric Testing and Empirical Evidence," M acmillan Press Ltd. (U.K).

Park, J.Y. and Phillips, P.C.B. [1988], "Statistical Inferences in Regressions with Integrated Processes: Part 1," Econometric Theory, 4; pp. 468-497.

Peel, D.A. [1993], “Non-Linear Risk Premia," Applied Financial Economics, 3; pp. 201-204.

Phillips, P.C.B. [1987], "Time Series Regression with a Unit Root," Econo metrica, 55; pp. 277-301.

Phillips, P.C.B. and Ouliaris, S. [1990], "Asymptotic Properties of Residual Based Tests for Cointegration," E conometrica, 58; pp. 165-193.

Phillips, P.C.B. and Perron, P. [1988], "Testing for Unit Roots in Time Series Regressions," Biometrika, 75; pp. 335-346.

Pittis, N. [1992], "Causes of the Forward Bias: Non-Rational Expectations Versus Risk Premia," Journal of M acroeconomics, 15; pp. 317-325. 
Stock, J.H. [1987], "Asymptotic Properties of Least Square Estimates of Cointegrating Vectors," Econometrica, 55; pp. 1035-1056.

Tse, Y.K. [1986], "The Spot and Forward Exchange Rates: Some Empirical Evidence of Singapore," Applied E conomics, 18; pp. 319-31.

Ukpolo, V. [1995], "Exchange Rate M arket Efficiency: Further Evidence from Cointegration Tests," Applied E conomics Letters, 2; pp. 196-198.

West, K.D. [1988], "Asymptotic Normality When Regressors Have a U nit Root," Econometrica, 56; pp. 1397-1418.

Wolff, C.C.P. [1987], "Forward Foreign Exchange Rates, Expected Spot Rates, and Premia: A Signal-Extraction Approach," Journal of F inance, 42; pp. 395-406.

Zietz, J. and Homaifar, G. [1994], "Exchange Rate Uncertainty and the Efficiency of the Forward $M$ arket for Foreign Exchange," Weltwirtschaft liches Archiv, 130; pp. 461-475. 